\title{
The Anomalous Merging of the African and North Atlantic Jet Streams during the Northern Hemisphere Winter of 2010
}

\author{
N. HARNIK AND E. GALANTI \\ Department of Geosciences, Tel Aviv University, Tel Aviv, Israel \\ O. MARTIUS \\ Institute of Geography, and Oeschger Centre for Climate Change Research, University of Bern, Bern, Switzerland \\ O. ADAM \\ Department of Earth Sciences, Eidgenössische Technische Hochschule Zurich, Zurich, Switzerland
}

(Manuscript received 27 August 2013, in final form 1 July 2014)

\begin{abstract}
The North Atlantic jet stream during winter 2010 was unusually zonal, so the typically separated Atlantic and African jets were merged into one zonal jet. Moreover, the latitude-height structure and temporal variability of the North Atlantic jet during this winter were more characteristic of the North Pacific. This work examines the possibility of a flow regime change from an eddy-driven to a mixed eddy-thermally driven jet. A monthly jet zonality index is defined, which shows that a persistent merged jet state has occurred in the past, both at the end of the 1960s and during a few sporadic months. The anomalously zonal jet is found to be associated with anomalous tropical Pacific diabatic heating and eddy anomalies similar to those found during a negative North Atlantic Oscillation (NAO) state. A Lagrangian back-trajectory diagnosis of eight winters suggests the tropical Pacific is a source of momentum to the Atlantic and African jets and that this source was stronger during the winter of 2010 . The results suggest that the combination of weak eddy variance and fluxes in the North Atlantic, along with strong tropical heating, act to push the jet toward a merged eddy-thermally driven state. The authors also find significant SST anomalies in the North Atlantic, which reinforce the anomalous zonal winds, particularly in the eastern Atlantic.
\end{abstract}

\section{Introduction}

One of the main characteristics of the midlatitude atmospheric flow is its organization into zonally oriented jet streams. Meteorologists have long noticed two types of jet streams: subtropical jets, which form because of meridional advection of angular momentum by the Hadley cells (e.g., Schneider 1977; Held and Hou 1980); and polar front jets, also referred to as eddy-driven jets, which form because of the convergence of momentum by baroclinically unstable eddies as they propagate away from their source region (e.g., Held 1975; Rhines 1975; Panetta 1993; Held 2000). Lee and Kim (2003) noted that these

Corresponding author address: Nili Harnik, Department of Geosciences, Tel Aviv University, P.O. Box 39040, Tel Aviv 6997801, Israel.

E-mail: harnik@tau.ac.il processes force both jets simultaneously, but under certain forcing conditions, eddy generation is close enough to the subtropical jet so that a single merged jet evolves (see also O'Rourke and Vallis 2013). Son and Lee (2005) further showed that a merged jet forms preferentially when the tropical heating is strong enough for the resultant subtropical jet to influence the growth of midlatitude eddies, while a double jet forms when tropical heating is weak enough to allow midlatitude eddies to grow more poleward and form a separate eddy-driven jet. The type of jet stream strongly affects the weather and, correspondingly, the climate in a given region. Eichelberger and Hartmann (2007) showed that the different jet types have very different temporal variability. While eddy-driven jets tend to meander latitudinally because of the nature of wave-mean flow feedbacks, the thermally driven or merged jets hardly shift in latitude, and instead their variability is associated more with a pulsation of the jet. 
While the above studies were all tested using models with zonally symmetric surface conditions, the main jet categorization and implied jet characteristics seem to apply to the real atmosphere when considering specific zonal sectors. In particular, the North Pacific jet has a vertical structure and temporal variability characteristic of a merged thermally-eddy-driven jet, while the North Atlantic jet is eddy driven, and it coexists with a subtropical jet that starts over the eastern Atlantic and extends over Africa and Asia (e.g., Son and Lee 2005; Eichelberger and Hartmann 2007). Furthermore, Li and Wettstein (2012) explicitly showed in reanalysis data that the Atlantic jet is mostly eddy driven, while the Pacific jet is both thermally driven and eddy driven.

In models, the transition from a single to a double jet occurs quite abruptly when external forcing parameters are gradually varied (e.g., Lee and Kim 2003; Son and Lee 2005). In particular, in Son and Lee (2005), the jet changed from an eddy-driven state to a merged eddy-thermally driven state when the tropical forcing was strengthened or the midlatitude baroclinicity weakened. Recently, Lachmy and Harnik (2014) showed that the important factor by which the midlatitude baroclinicity affects the jet stream type is the strength of the eddies. Moreover, a change in jet type can be induced by changing eddy damping while keeping the mean flow forcing fixed.

In the real atmosphere, jet type transitions have been noted to occur as part of the seasonal cycle and might occur in the future as the climate changes (e.g., Son and Lee 2005). It is possible that such changes may also occur interannually, in response, for example, to the regular interannual variability in tropical heating. Indeed, an examination of the interannual variability in the Atlantic jet structure suggests that, during some years, a single rather than double jet forms (Woollings et al. 2010b). Most striking is the winter of 2010 (hereafter, winter refers to December-March months, with the year referring to January-March), which exhibited an unusually strong and persistent negative phase of the North Atlantic Oscillation (NAO) and unusually cold and wet conditions over North America and Europe (Wang et al. 2010; Seager et al. 2010; Cattiaux et al. 2010; Vicente-Serrano et al. 2011; Santos et al. 2013). As shown below, during this winter, the Atlantic and African jets merged into one zonally oriented jet with a structure and variability more characteristic of the Pacific.

In this study, we propose that while the NAO phases are a manifestation of the eddy-driven jet meandering in latitude, some of the extremely negative NAO winters correspond to a change in the type of jet stream from an eddy-driven jet to a mixed thermally-eddy-driven jet, as is found in the Pacific. We will show that, along with negative NAO conditions, a weakening of midlatitude eddies and anomalously strong tropical diabatic heating were involved. After presenting the data and analysis methods (section 2), we characterize the anomalous conditions of the Atlantic jet during the winter of 2010, define an appropriate index to identify other months during which the jet was unusually zonal, and show that indeed during such winter months, the Atlantic and African jets merged (section 3). We then examine the change in eddy and thermal driving (sections $4 \mathrm{a}$ and $4 \mathrm{~b}$, respectively) and the possible role of the ocean, given large sea surface temperature (SST) anomalies in the Atlantic and Pacific (section 5). In section 6, we examine the relation between jet zonality and different atmospheric indices. We conclude with a discussion in section 7 .

\section{Data and analysis methods}

For much of the analysis, we use daily and monthlymean wind and temperature fields from the National Centers for Environmental Protection (NCEP) reanalysis data for 1949-2012 (Kalnay et al. 1996) (the results were unchanged when using data for 1958-2012). To verify robustness, we repeated many of the calculations using the 40-yr European Centre for Medium Range Weather Forecasts (ECMWF) Re-Analysis (ERA-40; Uppala et al. 2005) and the Interim ECMWF ReAnalysis (ERA-Interim; Dee et al. 2011) datasets. A Lagrangian back-trajectory analysis, which requires a higher resolution than NCEP, was done using ERAInterim data. To examine thermal forcing, we use NCEP and ERA-Interim radiative and sensible heat fluxes and precipitation to calculate total atmospheric column diabatic heating. We also use precipitation rates from the Global Precipitation Climatology Project (GPCP) Version 2.2 (Adler et al. 2003), which are the combined precipitation data developed and computed by the $\mathrm{Na}$ tional Aeronautics and Space Administration (NASA)/ Goddard Space Flight Center's Laboratory for Atmospheres as a contribution to the Global Energy and Water Cycle Experiment (GEWEX) Global Precipitation Climatology Project. We note that NCEP radiative fluxes only exist since 2002, while ERA-Interim and GPCP datasets start in 1979. We used the National Oceanic and Atmospheric Administration (NOAA) Climate Prediction Center (CPC) NAO index (based on the method in Barnston and Livezey 1987) and the Niño-3.4 index, calculated by CPC from the National Climate Data Center's (NCDC) extended reconstructed sea surface temperature (ERSST; Smith and Reynolds 2004; Smith et al. 2008). 
a) Winter 2010 mean $300 \mathrm{hPa} \mathrm{U}$

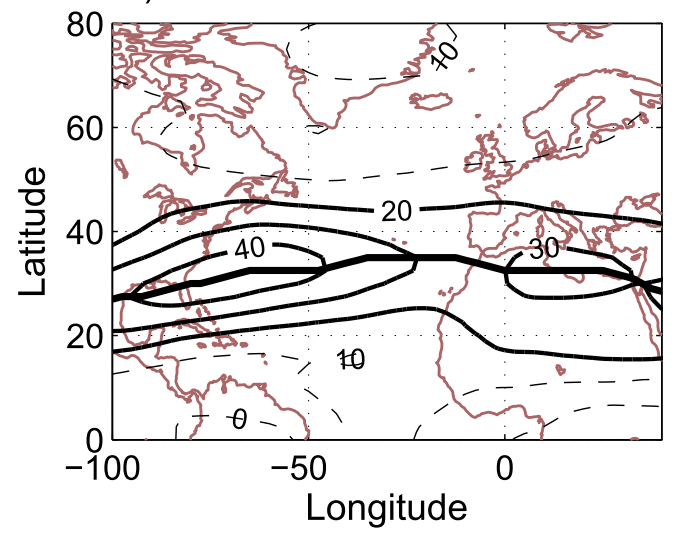

c) Winter 2010 mean $925-700 \mathrm{hPa} \mathrm{U}$

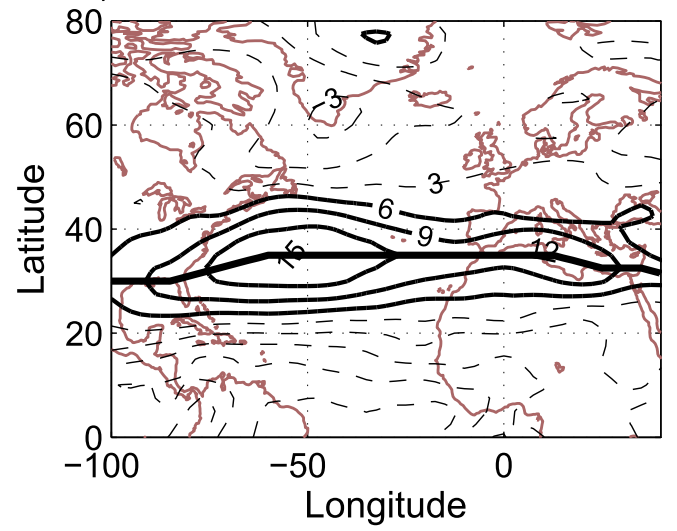

b) Climatological $300 \mathrm{hPa} \mathrm{U}$

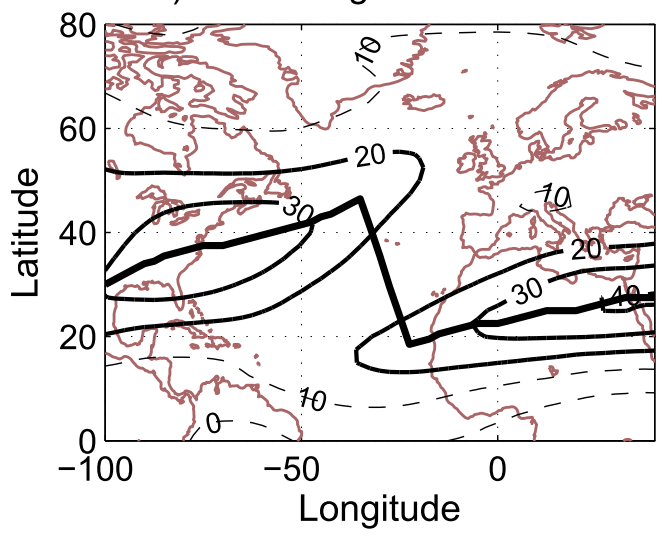

d) Climatological $925-700 \mathrm{hPa} \mathrm{U}$

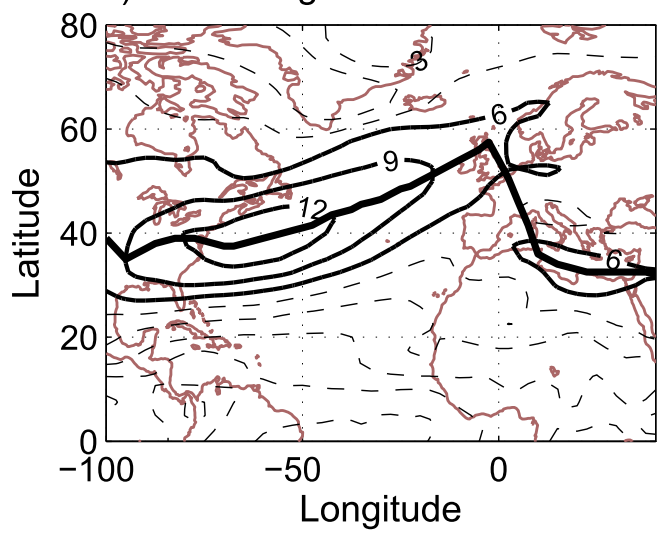

FIG. 1. The 300-hPa zonal wind (a) December 2009-March 2010 mean and (b) December-March climatology (1949-2012). (c),(d) As in (a),(b), but for $925-700 \mathrm{hPa}$. The jet axis (latitude of maximum zonal wind) is marked by the thick black lines. Contour intervals are 10 and $3 \mathrm{~m} \mathrm{~s}^{-1}$ for the upper- and lower-level winds, respectively. In (a),(b) contour values of $10 \mathrm{~m} \mathrm{~s}^{-1}$ and lower are dashed, while in (c),(d) values of $3 \mathrm{~m} \mathrm{~s}^{-1}$ and lower are dashed.

The ERSST data were also used to examine Atlantic sea surface temperatures.

To study the contribution and influence on synopticscale eddies, we divide the main daily-mean NCEP fields into short and long time scales using a simple boxcar filter with a cutoff of 10 days, so eddies are defined as the 10-day high-pass filtered data, while the mean flow is defined as the 10-day low-pass filtered data. We then calculate eddy fluxes as the low-pass covariances between high-pass fields. Examining meridional wind variances using a 24-h difference filter that spans 2-8-day periods gave similar results. A Lagrangian analysis of the momentum sources of the jets in the Atlantic basin and over Africa is done by calculating back-trajectories up to one week back (for details, see Martius and Wernli 2012; Martius 2014). To examine possible causes and effects of an anomalously zonal jet state, we calculate composites of various fields by averaging monthly data over subsets of the December-March winter months. Statistical significance is calculated from the anomaly field composites using a standard two-sided Student's $t$ test against climatology, with anomaly defined as the deviation from a monthly climatological seasonal cycle. Regions for which the anomalies are significant are shaded, both on plots of the full field and on plots of anomaly field composites. Unless otherwise noted, the results we present will be from the NCEP reanalysis data for the years 1949-2012, but we verified that the main features of the composite analyses hold also for ERA-40 and ERA-Interim.

\section{The unusually zonal Atlantic-African jet state \\ a. The anomalous conditions during winter 2010}

One of the anomalous features of the northern winter 2010 in the Atlantic is the merging of the Atlantic and African jets. Figure 1 shows the upper- and lower-level jet during this winter alongside climatological winds. For this part of the analysis, we use daily- and monthly-mean 


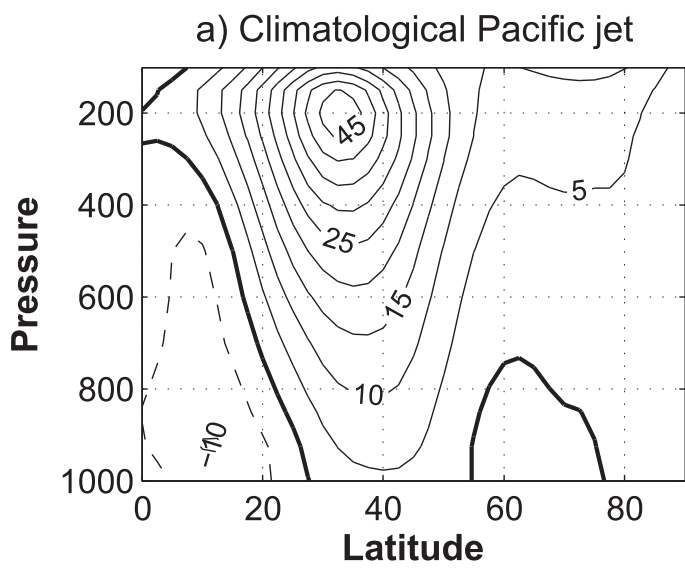

c) Winter 2009-10 Atlantic jet

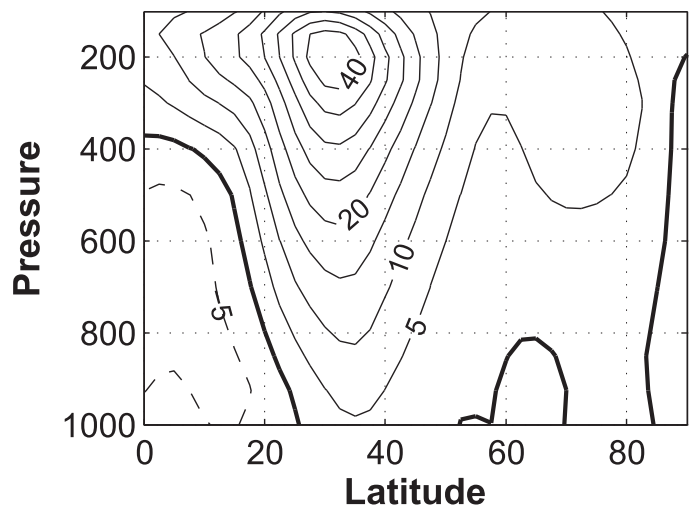

winds from the NCEP reanalysis for 1949-2012 (Kalnay et al. 1996). We see that, during 2010, the Atlantic jet became zonally oriented, while the African jet shifted a bit poleward so that the two jets merged into one. An examination of the latitude-height structure of the Atlantic jet during this winter, when compared to the climatological Atlantic and Pacific jets (Fig. 2), shows more similarity to the Pacific, which has a single jet with strong baroclinic and barotropic components. Consistent with Eichelberger and Hartmann (2007), we find that the anomalous jet configuration during this winter was unusually persistent, and its temporal variability was more characteristic of the jet variability in the Pacific than in the Atlantic (Fig. 3).

\section{b. The zonal jet index}

The main feature that characterizes the merged Atlantic and African jets is their unusual zonality. We therefore define a zonal jet index (ZJI), which will allow us to objectively identify other such periods. Looking at the $300-\mathrm{hPa}$ zonal wind field (we used either monthly or seasonal averages), we first find the latitude of the jet axis $\left[\varphi_{\mathrm{ja}}(\lambda)\right]$, defined at each longitude $\lambda$ as the latitude $\varphi$ with maximum zonal wind b) Climatological Atlantic jet

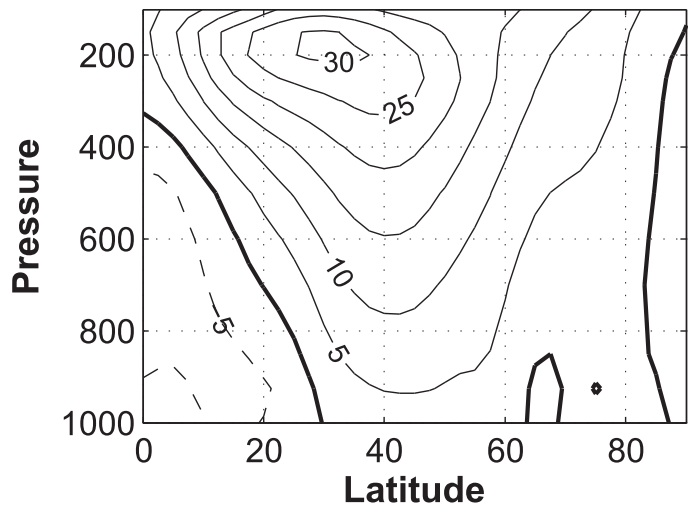

FIG. 2. Latitude-height plots of the December-Marchmean zonal wind: (a) climatological values, averaged zonally over the Pacific $\left(120^{\circ} \mathrm{E}-120^{\circ} \mathrm{W}\right)$; (b) climatological values, averaged zonally over the Atlantic $\left(100^{\circ} \mathrm{W}-0^{\circ}\right)$; and (c) December 2009-March 2010 mean over the Atlantic $\left(100^{\circ} \mathrm{W}-0^{\circ}\right)$. The contour interval is $5 \mathrm{~m} \mathrm{~s}^{-1}$, the zero line is marked by a thick line, and negative values are dashed.

values (thick black lines in Fig. 1), and calculate its zonal derivative $\left(d \varphi_{\mathrm{ja}} / d \lambda\right)$. This derivative will have the largest magnitude (large negative values) at the point where the jet axis jumps from the Atlantic to the African jet. During years when the jet is very zonal, as in Fig. 1a, this gradient will be small (in absolute value) everywhere. Using the monthly or seasonal averaged winds, we calculate the maximum absolute value of the zonal gradient of the latitude of the jet axis and define the ZJI as the monthly anomaly of this quantity from its climatological seasonal cycle. Defined this way, the ZJI will be anomalously negative during months with an unusually zonal jet. Figure $4 \mathrm{a}$ shows the corresponding ZJI time series using monthlymean zonal-mean winds at $300 \mathrm{hPa}$. The figure shows all months, but we marked with solid dots those DecemberMarch months for which the ZJI anomaly (of both signs) exceeds one standard deviation (dashed lines). Note that anomalously zonal jet configurations (negative ZJI anomaly) have occurred during all seasons, but we only concentrate on winter months. We see that the ZJI during the winter of 2010 is negative and anomalously persistent, with all four winter months being strongly negative. This is highlighted when we examine the ZJI 
a) Dec-Mar mean $300 \mathrm{hPa}$ zonal wind averaged over the Pacific region (120E-120W)

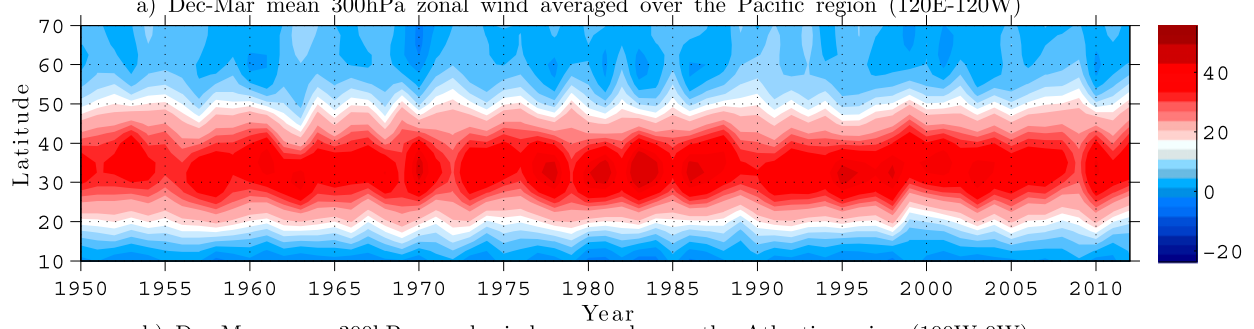

b) Dec-Mar mean $300 \mathrm{hPa}$ zonal wind averaged over the Atlantic region (100W-0W)

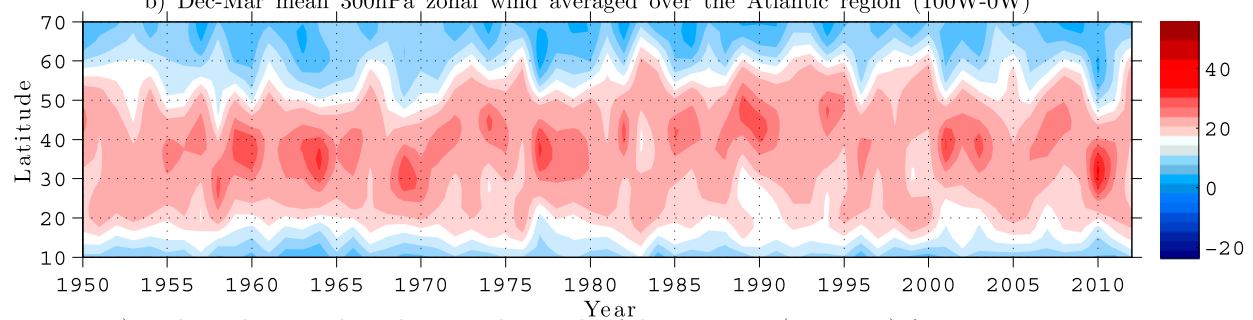

c) Daily $300 \mathrm{hPa}$ zonal wind averaged over the Atlantic region $(100 \mathrm{~W}-0 \mathrm{~W})$ for winter 2010

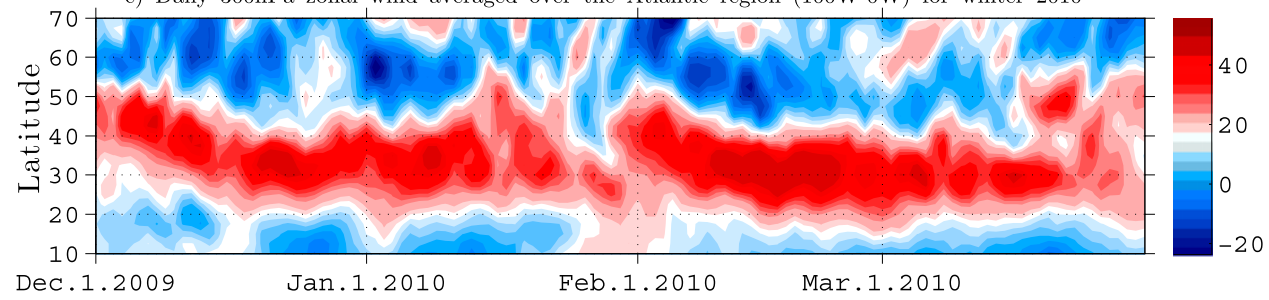

FIG. 3. (a) Latitude-year plots of the winter-mean (December-March) 300-hPa zonal wind ( $\mathrm{m} \mathrm{s}^{-1}$ ) averaged over the Pacific region $\left(120^{\circ} \mathrm{E}-120^{\circ} \mathrm{W}\right.$ average). (b) As in (a), but for the Atlantic region $\left(100^{\circ} \mathrm{W}-0^{\circ}\right.$ average $)$. (c) Day-latitude plot of $300-\mathrm{hPa}$ zonal wind in the Atlantic region $\left(100^{\circ} \mathrm{W}-0^{\circ}\right)$ for the period of 1 Dec 2009-31 Mar 2010.

calculated from the December-March-mean 300-hPa zonal wind (Fig. 4b). We also see that there are other months and winters with a negative ZJI, with more such months occurring in the earlier half of the time series and other very anomalous ZJI winters occurring only prior to 1971.

\section{c. The characteristic negative ZJI jet structure}

Figure 5a shows a composite of monthly-mean 300-hPa winds for winter months with strongly negative ZJI values, based on a one standard deviation threshold (the dots below the lower dashed line in Fig. 4a). We see that indeed during months with anomalously negative ZJI values, the Atlantic and African jets merged to one unusually zonal jet. The corresponding zonal wind anomaly composite (Fig. 5b), plotted along with the composite jet axis (thick black line), shows an equatorward shift of the Atlantic jet and a poleward shift of the jet over easterncentral Africa. In contrast, the composite for anomalously positive ZJI (the dots above the upper dashed line in Fig. 4a) shown in Fig. 5c shows a strongly slanted Atlantic jet that is well separated from the African jet, but the pattern is not statistically significant. This is due to the large variability in split-jet structures, which partly reflects the trimodal structure of the distribution of Atlantic jet latitudes (Woollings et al. 2010a). Also shown, for reference, is the corresponding composite for negative NAO months (based on one standard deviation; Fig. 5d). We see that, while the Atlantic jet is similar between the negative NAO and negative ZJI composites, the African jet does not shift poleward as much for the negative NAO, so the two jets are not connected as in the winter of 2010. In what follows, we only examine the negative ZJI state and note that the index was only tested for the monthly- and wintermean Atlantic-African jets, so that these findings do not necessarily work as an indication of jet merging in other regions and on other time scales.

\section{Dynamical characteristics of anomalously zonal jet months}

In this section, we examine the characteristics of various circulation features during months with an unusual zonal Atlantic jet configuration, with the aim of understanding what drove the jet to shift to a merged state and what maintains it. In particular, we examine changes in eddy and thermal driving and how they related to the changes in the 

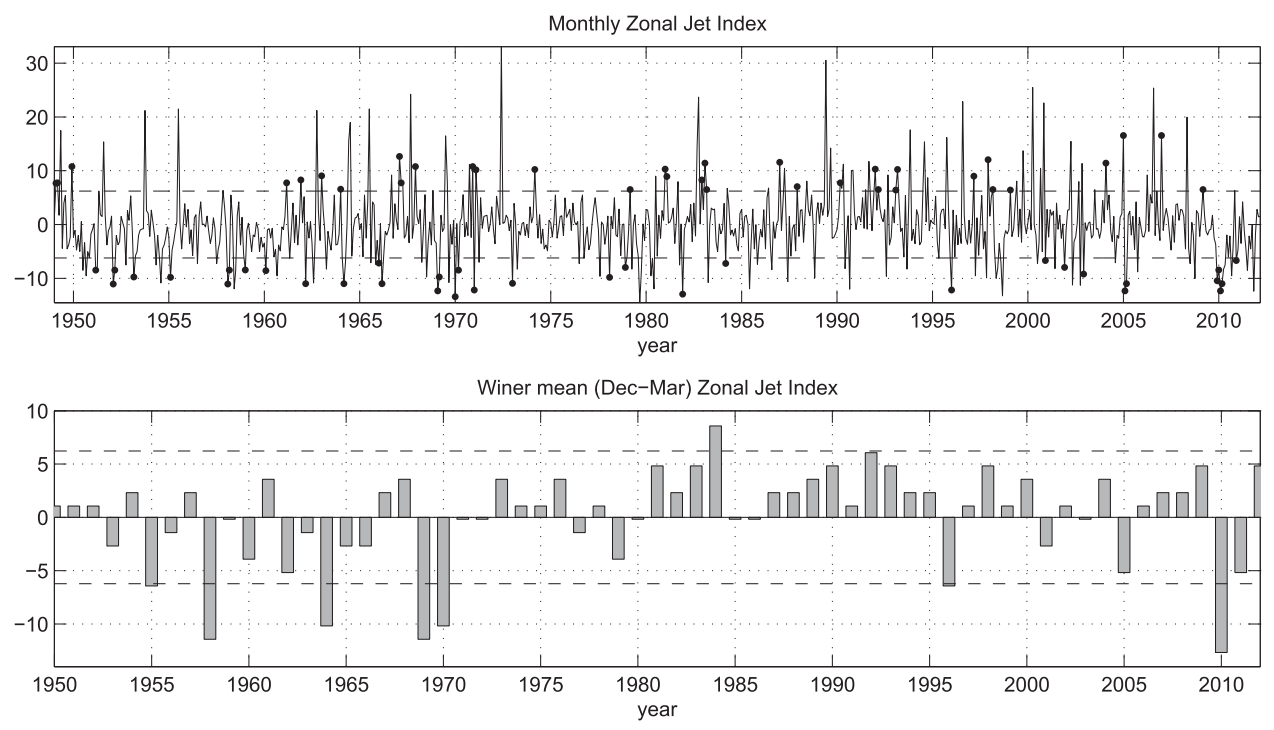

FIG. 4. Time series of the ZJI based on (top) monthly and (bottom) winter (December-March mean) $300-\mathrm{hPa}$ zonal winds. The dashed lines mark one standard deviation (the mean is zero by construction) based on the monthly data. In (top), all months are shown, and those December-March months with an anomaly larger than one standard deviation (of either sign) are marked with filled circles.

mean flow. We start by calculating negative ZJI composites of various fields. These composites consist of averaging monthly data over those December-March months for which the ZJI is negative by more than one standard deviation (the dots below the lower dashed line in Fig. 4a).

\section{a. Eddy driving}

One of the main sources of variance to the Atlantic jet structure is a change in the synoptic-scale eddies, which nonlinearly interact with the jet. Figures $6 a-c$ show the negative ZJI composites of eddy meridional wind variance, chosen to represent the midlatitude storm track, alongside its climatological field. As expected, the storm track is more zonally oriented during zonal jet years, with its eastern edge reaching Spain rather than Great Britain. Apart from an equatorward shift, however, the eddies weaken during zonal jet years (this is despite the ZJI composite being an average over many fewer months than the climatology). This is most evident from the anomaly composite (Fig. 6c). This overall weakening is also evident in the anomalous eddy heat and momentum fluxes (Figs. 6d,e). While in the climatology, the eddy heat fluxes are mostly positive and assume the northeastward slant of the Atlantic jet; during zonal jet months, the eddy heat flux anomaly (Fig. 6d) is mostly negative over the central and eastern North Atlantic and positive over Europe, suggesting eddy growth is greatly suppressed but extends further eastward, consistent with less efficient baroclinic growth in a more zonal storm track. Eddy momentum fluxes, which are typically directed poleward over most of the storm track region, are significantly weaker during zonal jet years (Fig. 6e), with small increases in the subtropics over the eastern Atlantic and Africa because of the equatorward shift of the eddies. This decrease results in an anomalous eddy momentum flux convergence (EMFC; Fig. 6f), which accelerates the flow south of $40^{\circ} \mathrm{N}$ and decelerates it poleward of $40^{\circ} \mathrm{N}$, reinforcing the observed zonal wind anomaly (Fig. 4b). ${ }^{1}$

It is important to note that the analysis presented shows instantaneous effects, indicating consistency and not causality. We do not expect to be able to establish causality from observations because the eddies and the jet create feedback for each other and the time scales are submonthly. The above results are, however, consistent with a transition to a merged jet state, as follows. In the eddy-driven jet regime, the tropical thermally driven direct-mean meridional circulation that continuously forces westerly winds at the subtropics is weak, so the eddy momentum flux convergence dominates and forces a jet in midlatitudes. When the midlatitude eddies and their associated eddy momentum flux convergence are weaker, as is observed to be the case during zonal jet years, the thermal driving of the jet can play a more significant role. The equilibrated jet in this case is more

\footnotetext{
${ }^{1}$ We also examined the contribution of zonal momentum flux convergence and found it to be negligible compared to the meridional component.
} 
a) U(300hPa) negative ZJI composite

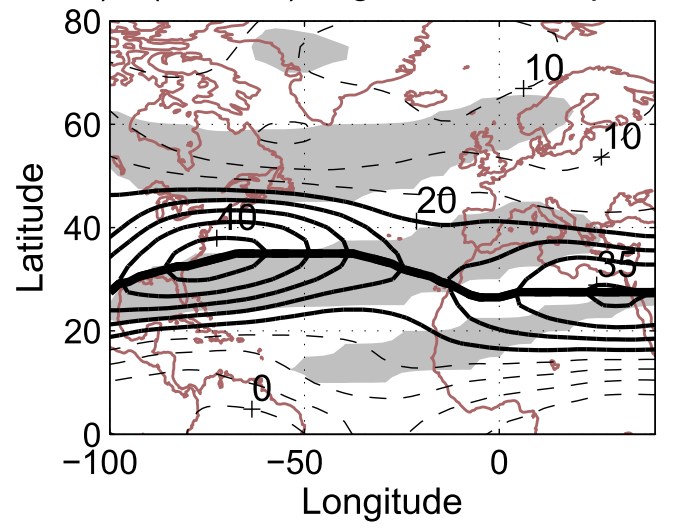

c) Positive ZJI composite

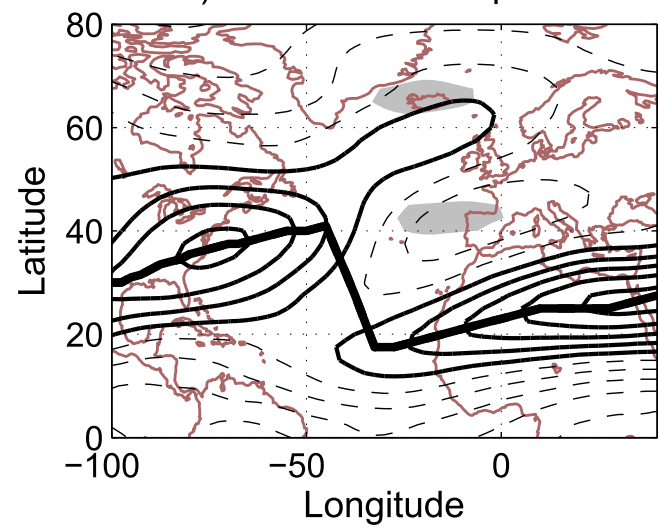

b) Negative ZJI anomaly composite

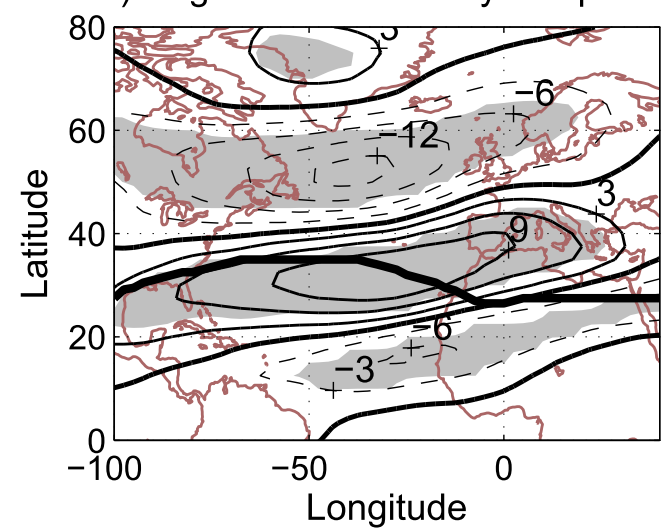

d) Negative NAO composite

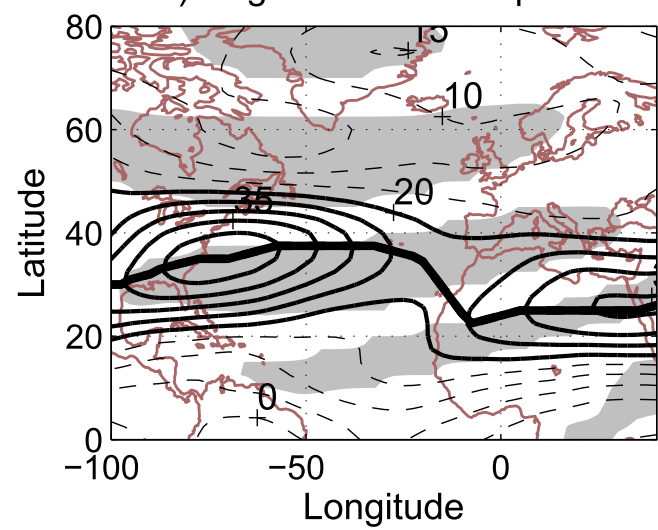

FIG. 5. Composites for anomalously zonal jet months (anomalously negative ZJI) of (a) 300-hPa $U$ and (b) 300-hPa $U$ anomaly (the deviation from the climatological seasonal cycle). (c) As in (a), but for months with anomalously positive ZJI values. (d) As in (a), but for months with an anomalously negative NAO phase. Shading represents regions for which the composites are significant at $99.9 \%$ based on a two-sided Student's $t$ test against climatology. In (a),(c),(d), contour interval is $5 \mathrm{~m} \mathrm{~s}^{-1}$, and values of $20 \mathrm{~m} \mathrm{~s}^{-1}$ or smaller are dashed. In (b), contour interval is $3 \mathrm{~m} \mathrm{~s}^{-1}$, negative values are dashed, and the zero line is thick.

equatorward and is affected by both thermal and eddy driving (cf. Son and Lee 2005: Lachmy and Harnik 2014). At the same time, the transition to a merged jet state will also weaken eddy amplitudes by trapping the upper-level disturbances equatorward of the latitude of strongest surface baroclinicity and making baroclinic growth less efficient (Nakamura and Sampe 2002).

\section{b. Thermal driving}

Son and Lee (2005) showed that stronger tropical heating leads to a single merged jet, while weaker heating leads to a strong eddy-driven jet alongside a weaker subtropical jet. Li and Wettstein (2012) examined observed monthly-mean Northern Hemisphere winter data and showed that in the Pacific, monthly variations in the jet stream correlated strongly with both midlatitude eddy-momentum flux convergence and various proxies of thermal driving. In the Atlantic, on the other hand, they found a strong correlation only with the eddy momentum flux convergence. Given the similarity between the Atlantic and Pacific jets during negative ZJI months, we expect thermal driving to play a larger role during such months. Following Li and Wettstein (2012) we use total column-integrated diabatic heating calculated directly from the monthly reanalyses products by summing the net shortwave and longwave radiative fluxes into the atmospheric column (top of atmosphere and surface fluxes), the surface vertical sensible heat flux, and the latent heat released by local precipitation [Eq. (5) in Trenberth and Solomon (1994)]. Because radiation data in NCEP reanalysis are only given since 1992, we also use data from the ERA-Interim, which starts in 1979.

Figures $7 \mathrm{a}, \mathrm{b}$ show the negative ZJI monthly anomaly composites for both reanalyses. We see a significant Atlantic tripole pattern, with anomalous heating over the midlatitude Atlantic, a large negative anomaly in the northern part of the Atlantic just south of Greenland, and a weak anomalous diabatic cooling in the subtropical 

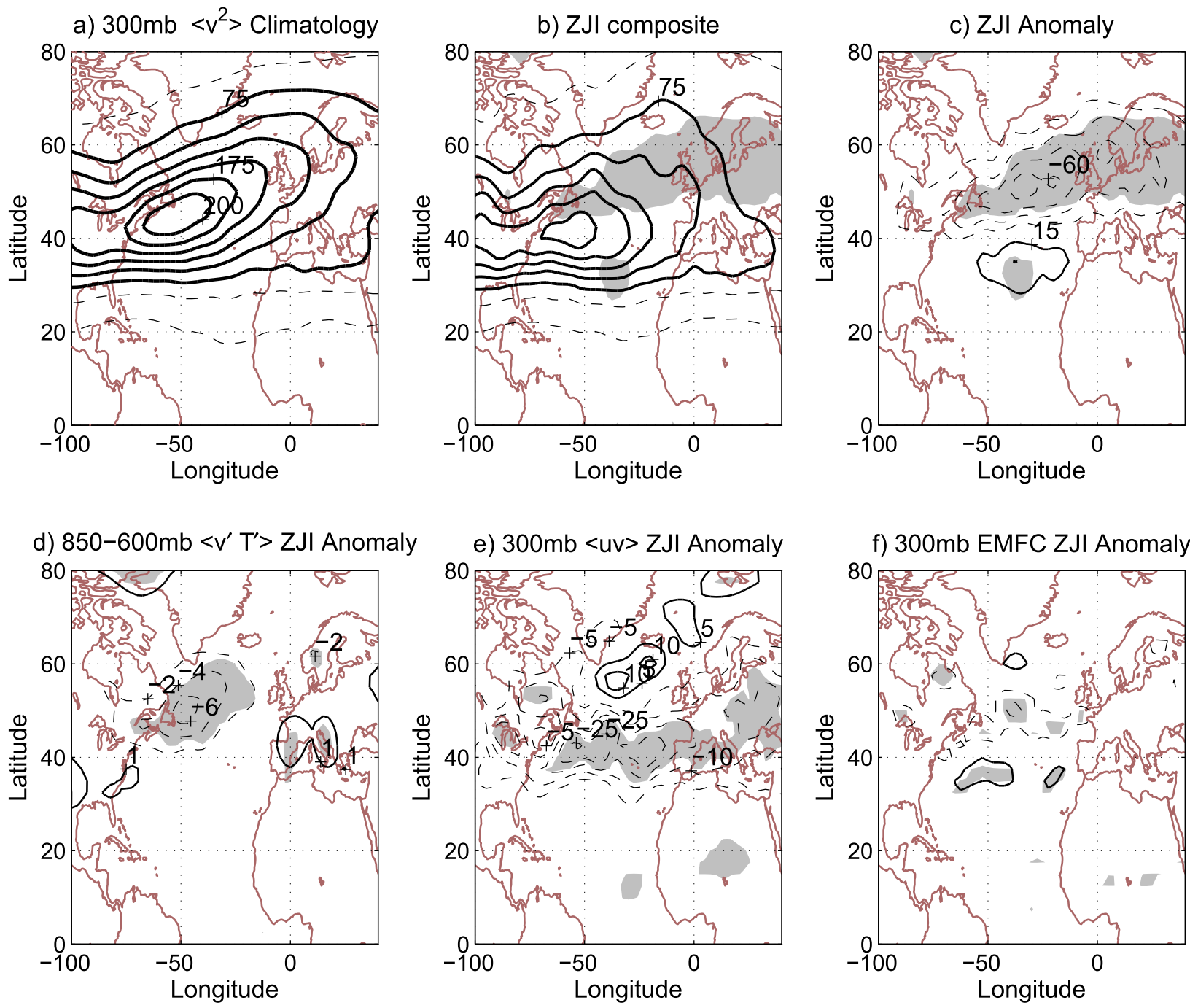

FIG. 6. The 300-hPa eddy $v$ variance $\left\langle v^{\prime 2}\right\rangle$ [with (') denoting a 10-day high-pass field, and $\langle()\rangle$ denoting the 10-day low-pass field] for (a) December-March climatology. The composite of negative ZJI December-March months of (b) the total field and (c) its anomaly with respect to the climatological seasonal cycle. (d)-(f) Anomaly composites as in (c), but for (d) 850-600-hPa mean eddy heat flux $\left\langle v^{\prime} T^{\prime}\right\rangle$, (e) 300-hPa eddy momentum flux $\left\langle v^{\prime} v^{\prime}\right\rangle$, and (f) meridional eddy momentum flux convergence (cosine squared weighted meridional gradient of $\left\langle u^{\prime} v^{\prime}\right\rangle$ ). The shading represents regions for which the composites are significant at the $99 \%$ value. Contour intervals are as follows: (a),(b) $25 \mathrm{~m}^{2} \mathrm{~s}^{-2}$, where values of $75 \mathrm{~m}^{2} \mathrm{~s}^{-2}$ and lower are dashed; (c) $15 \mathrm{~m}^{2} \mathrm{~s}^{-2}$; (d) $2 \mathrm{~K} \mathrm{~m} \mathrm{~s}^{-1}$ with $\pm 1 \mathrm{~K}$ contour added; (e) $5 \mathrm{~m}^{2} \mathrm{~s}^{-2}$; and (f) $2 \times 10^{-5} \mathrm{~K} \mathrm{~s}^{-1}$. In (c)-(f), negative values are dashed. All fields calculated using NCEP reanalysis data from 1948 to 2012.

Atlantic, which is stronger in NCEP than in ERA-Interim, similar to what is found for a negative NAO. In the tropics, however, we do not see a significant signal over the Atlantic, but we do see significant anomalous heating in the equatorial Pacific. These anomalies are typical of El Niño conditions, which were observed during winter 2010. This raises the possibility that tropical Pacific diabatic heating affects the Atlantic jet, and under the right conditions, an anomalously strong tropical Pacific heating can strengthen the Atlantic subtropical jet enough to cause it to transition from a double to a single jet, as seen during these months. This is, in fact, consistent with
Fig. 2 of Li and Wettstein (2012), which shows a zonal wind anomaly in the midlatitude Atlantic in composites of extreme tropical Pacific diabatic heating but not in composites of tropical Atlantic diabatic heating.

Because latent heat release is a major component of the diabatic heating fields (e.g., Romanski and Rossow 2013), but this field is highly dependent on the analysis model parameterizations, we also examine monthly GPCP precipitation fields (Adler et al. 2003). The precipitation rate ZJI anomaly, shown in Fig. 7c, looks quite similar to the diabatic heating anomalies, though there is no clear negative anomaly in the subtropical Atlantic, and the 

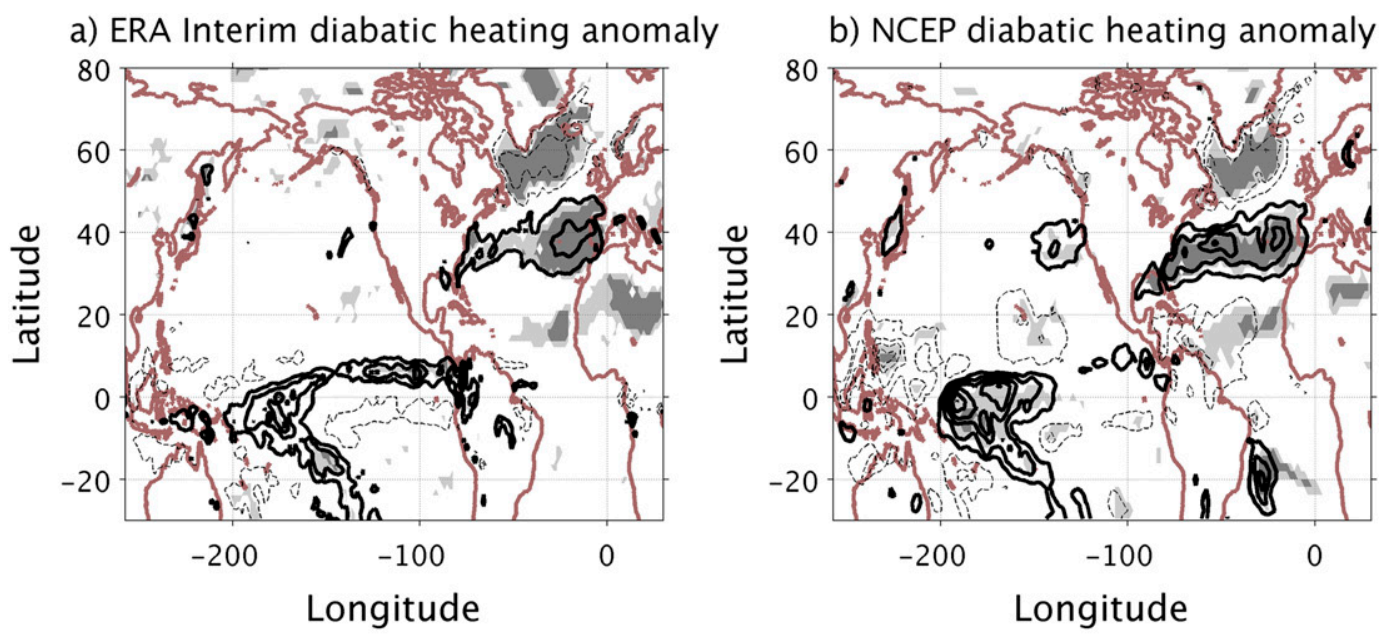

c) GPCP precipitation anomaly

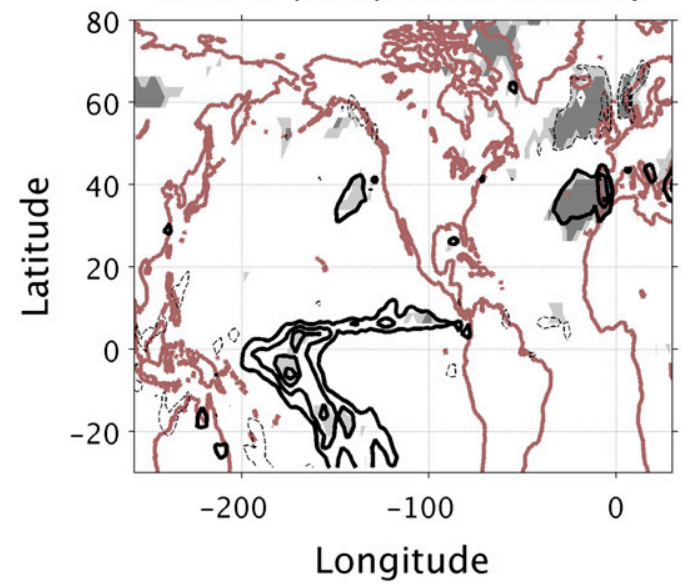

d) Month 0 NCEP $\omega$ anomaly

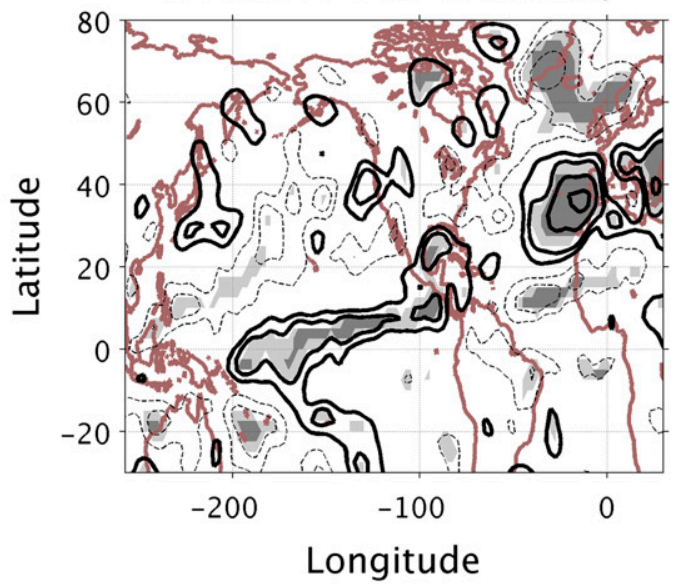

e) Month -2 NCEP $\omega$ anomaly
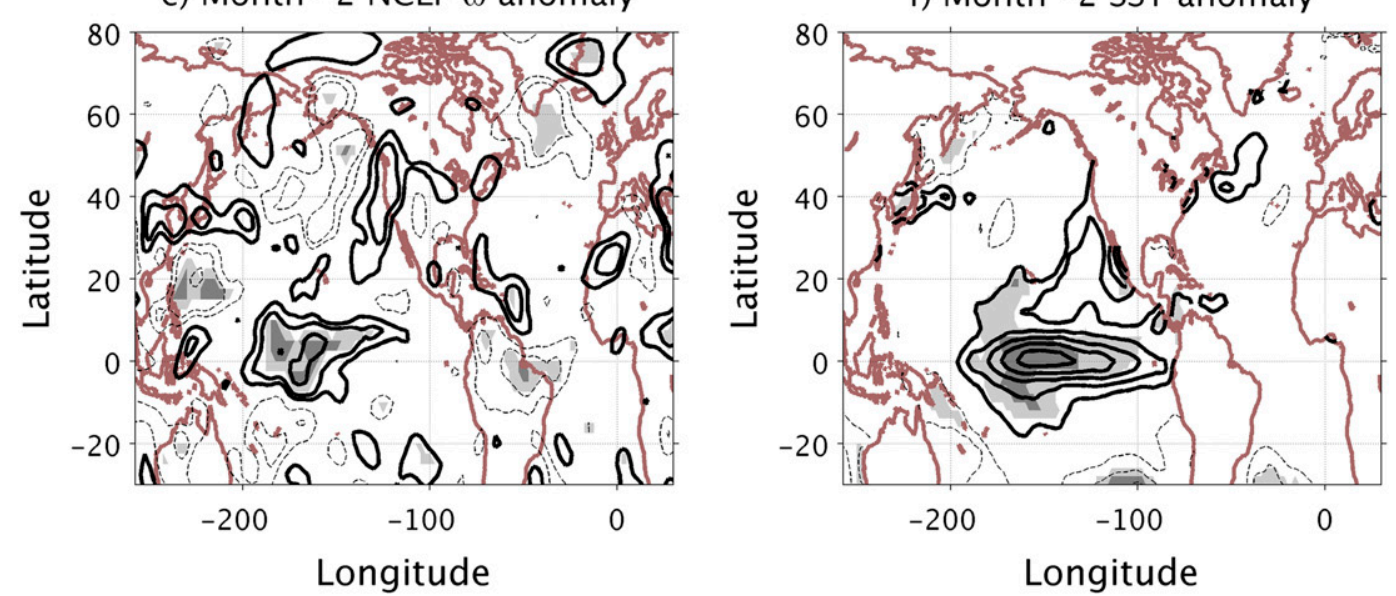

FIG. 7. Negative ZJI composites of monthly anomalies of the following fields: (a) ERA-Interim diabatic heating (1979-2012), (b) NCEP reanalysis diabatic heating (2002-12), (c) GPCP precipitation rate (1979-2012), NCEP 600400-hPa mean vertical pressure velocity $\omega$ (1949-2012; negative values in solid) for time lags (d) 0 and (e) -2 months, and (f) SST anomaly (relative to 1949-2012) for time lag -2 months. Contour intervals are as follows: diabatic heating $=30 \mathrm{~W} \mathrm{~m}^{-2}$, precipitation $=1 \mathrm{~mm} \mathrm{day}^{-1}$, Vertical pressure velocity $=0.01 \mathrm{hPa} \mathrm{s}^{-1}$ with $\pm 0.005 \mathrm{hPa} \mathrm{s}^{-1}$ contour added, and SST $=0.15 \mathrm{~K}$. Negative values are dashed, except for vertical pressure velocity, for which positive values are dashed. Zero contours are omitted. Gray shadings represent $95 \%$ and $99 \%$ significance levels (darker marks represent higher significance). 
positive midlatitude anomaly is only over the eastern half of the Atlantic. As with diabatic heating, there is a significant positive anomaly over the central and eastern Pacific and even a hint of a midlatitude eastern Pacific dipole.

We note from Fig. 4 that a significant number of the negative ZJI months occurred prior to 1979; thus, the diabatic heating and precipitation composites consist of only 10 negative ZJI months after 2002 and 3 more between 1979 and 2001. To extend the composite analysis back in time and include the zonal jet months prior to 1979 , we examine vertical pressure velocity $(\omega)$ using NCEP reanalysis data for the period 1949-2012. As was shown by Li and Wettstein (2012), the climatological $\omega$ pattern captures the diabatic heating and precipitation fields well. The negative ZJI $\omega$ anomaly composite is shown in Fig. 7d. For clarity, we plot negative values (upward motion), which indicate diabatic heating, in solid. We see anomalous ascent over the tropical Pacific and a tripole anomaly pattern over the Atlantic. As with the precipitation anomalies, the significant midlatitude ascent occurs only over the eastern half of the Atlantic. To examine causality, we calculate time-lagged composites of all the above fields. Figure $7 \mathrm{e}$ shows a composite of the $\omega$ field 2 months prior to the anomalously negative ZJI months. We see a significant tropical Pacific anomaly (with the anomaly starting to be significant already in month -3 , not shown), suggesting the tropical Pacific heating at least partially drives the anomalous jet state. The time lead of tropical Pacific heating is also evident from the SST anomalies, which at time lag of -2 months (Fig. 7f) show a very clear positive anomaly that is maximal in the central tropical Pacific and consistent with El Niño conditions. This tropical Pacific anomaly develops as early as 3 months before the jet becomes zonal and diminishes only after the peak negative ZJI month (not shown).

The El Niño conditions during winter 2010 prompted Santos et al. (2013) to examine the role of the tropical Pacific in forcing the variability of the Atlantic jet, but contrary to our findings, they did not find a significant signal. To further verify the robustness of our results, we repeated the composite calculations using subsets of the data. Figure 8a shows the composite of $\omega$ anomalies at 0 time lag for 1949-2011, excluding the four winter months of winter 2010. We see significant ascent in the tropical Pacific (with anomalies being significant as early as month -3 ), suggesting the tropical Pacific forcing is not unique to winter 2010. We also repeat the analysis for 1979-2012 (Figs. 8b,c) and find much weaker anomalies with no significant signal when we remove the winter 2010 months, similar to Santos et al. (2013) (who used ERA-Interim from 1979). To more closely examine the monthly signals, we define a tropical Pacific ascent index (TPAI) as the average of $\omega$ (weighted by cosine latitude) in a tropical box extending from $15^{\circ} \mathrm{S}-$ $15^{\circ} \mathrm{N}, 200^{\circ}-100^{\circ} \mathrm{W}$ (marked in blue on Fig. 8a) and plot it against the monthly December-March ZJI time series, with the winter months up to 1978 in red and the rest in blue. For reference, we mark the line of $-1 \mathrm{ZJI}$ standard deviation and mark the 2010 winter months by large circles. We see that about two thirds of the negative ZJI months also have negative TPAI values (anomalous ascent), with more negative ZJI months with negative TPAI before 1979. The winters of 2010, 1970, 1969, and 1958, which each had a negative ZJI for a few consecutive months (Fig. 4), had anomalously negative TPAI values. Overall, the results support our notion that the tropical Pacific contributes to the anomalous merging of the Atlantic and African jets during a few very anomalous months.

To further examine the role of tropical Pacific heating on the Atlantic jets, we use a back-trajectory calculation similar to that conducted by Martius and Wernli (2012) and Martius (2014). The subtropical jet is forced to first order by the export of angular momentum from the tropics into the subtropics by the thermally driven overturning circulation, with eddies modulating the angular momentum budget in the subtropics. During winter, however, the contribution of eddies to the angular momentum at the jet peak is secondary compared to contribution of the overturning circulation (e.g., Bordoni and Schneider 2010; Martius 2014). This allows a cleaner interpretation of the back trajectories as an indication of where the transport of angular momentum from the tropics into the subtropics occurs. Here we use this analysis to examine the tropical Pacific contribution to air flowing into the Atlantic jet entrance $\left(90^{\circ}-45^{\circ} \mathrm{W}\right)$ and African jet $\left(30^{\circ} \mathrm{W}-30^{\circ} \mathrm{E}\right)$ regions. Since the analysis is very computationally intensive, it has only been carried out for 8 winters (December-February, year corresponding to January-February), using ERA-Interim data. Based on Fig. 4b, we chose 1996, 2005, and 2010 as representative negative ZJI winters, while 1997 and 2006-09, which were not negative ZJI years, were chosen for comparison. For each day during a given winter, the back-trajectory calculation first picks the grid points that constitute the jet based on characteristics of a subtropical jet: wind velocities above $40 \mathrm{~m} \mathrm{~s}^{-1}$ and the vertical shear concentrated at upper levels (see Koch et al. 2006). These grid points serve as starting points for the back-trajectory calculation, which is run for 7 days $(168 \mathrm{~h})$. Figure 9 shows the fraction of the total number of trajectories that cross each grid point over the entire 7day period as well as the region from which the calculation is started (thick black contour), calculated for the negative 
a) Month $0 \omega$ anomaly no $2009-10$

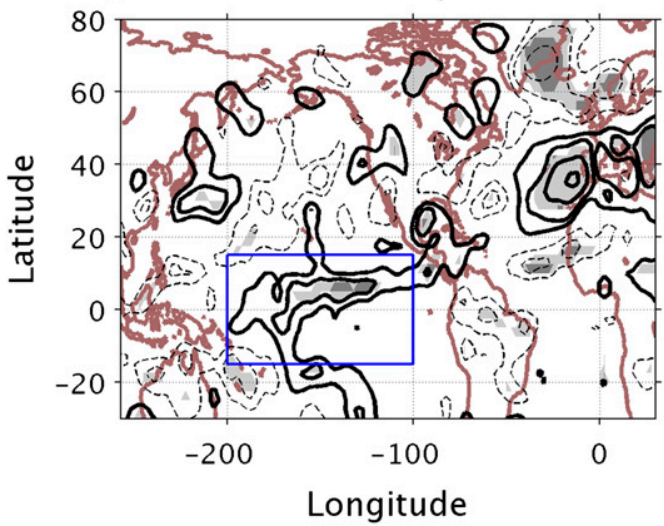

c) $1979-2012$, no $2009-10$

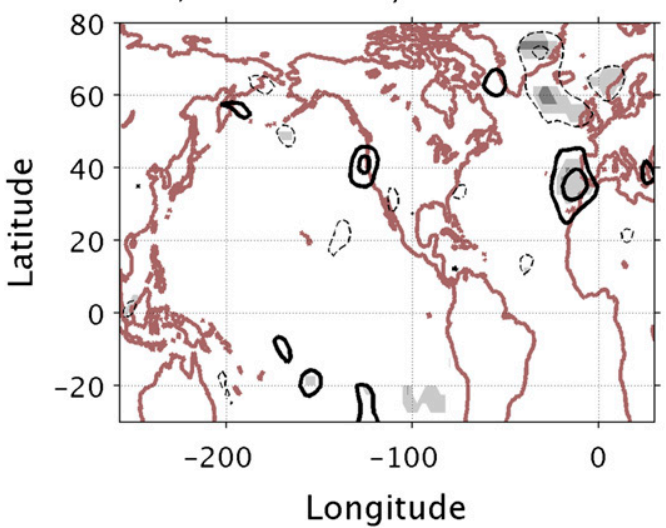

b) $1979-2012$ all years

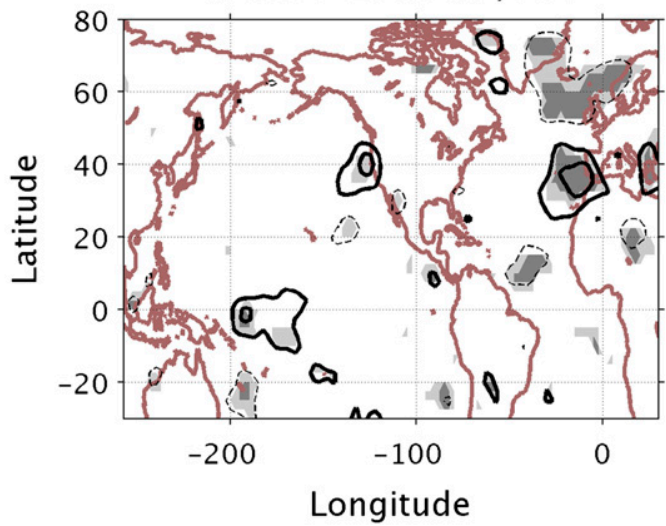

d) Dec-Mar monthly indices

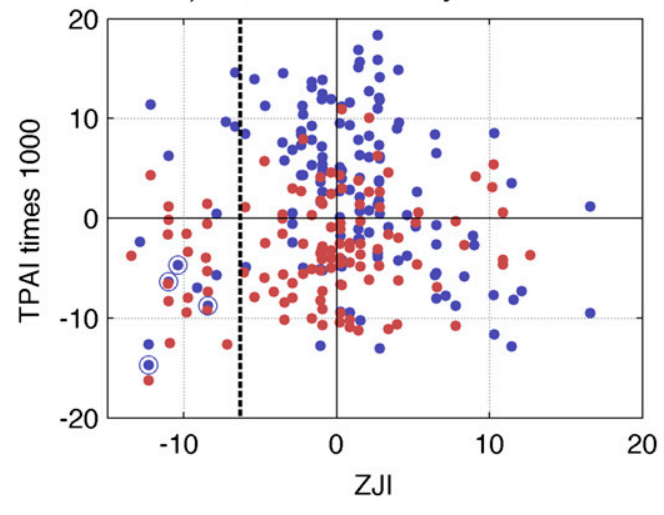

FIG. 8. Negative ZJI composites of monthly anomalies of NCEP 600-400-hPa mean vertical pressure velocity $\omega$ for subsets of the data used to create Fig. 7d: (a) winters 1949-2011, with December 2009-March 2010 excluded; (b) winters 1979-2011, all months; and (c) winters 1979-2011, excluding December 2009-March 2010. Units and contours for (a)-(c) are as in Fig. 7d. (d) A scatterplot of the December-March TPAI vs ZJI values, with winter months before December 1978 in red. The months of winter 2010 are also marked by large circles. For reference, we mark the -1 standard deviation of ZJI by a dashed black line.

ZJI winters of 1996, 2005, and 2010 (Figs. 9a and 9b for the Atlantic and African jets, respectively) and for five other winters (1997 and 2006-09; Figs. 9c and 9d for the Atlantic and African jets, respectively). Also shown is the difference between the two plots (Figs. 9e and 9f for the Atlantic and African jets, respectively). Examining the back trajectories of the African subtropical jet, we see that during the years when the jet has a more typical structure (Fig. 9d), one of the main regions from which air parcels ascend to the upper troposphere, enter the northward directed branch of the Hadley cell, and then reach the jet is tropical South America (Martius 2014). During the negative ZJI winters (Fig. 9c), a smaller-than-usual fraction of trajectories emanate from this region, seen as a blue region over northernmost South America in Fig. 9f. At the same time, more air parcels reached the African subtropical jet by flowing zonally from as far away as South Asia over India (e.g., Fig. $9 \mathrm{~b}$ and the orange region over South Asia and the subtropical Pacific in Fig. 9f). Examining the Atlantic jet, we see that, during negative ZJI years, an anomalously large fraction of the air parcels moved northward from the equator into the subtropics from the tropical Pacific, in particular over the eastern part (orange region over the tropics between $120^{\circ}$ and $90^{\circ} \mathrm{W}$ in Fig. 9e). ${ }^{2}$ In addition, more air flows into the jet from the subtropics, consistent with a strongly zonal flow, and less comes from midlatitudes, South America, or the tropical Atlantic. The African jet also shows a greater contribution

\footnotetext{
${ }^{2}$ We note that 1996 and 2005 were chosen because their ZJI values were the most negative; however, these may not be the most optimal years for detecting a tropical Pacific role, as their TPAI values were positive. An examination of the winter of 2010 back trajectories separately from the winters of 1996 and 2005 shows an increase in the number of trajectories coming from the tropical Pacific during 2010, in particular in the western part (between $120^{\circ} \mathrm{E}$ and $\left.150^{\circ} \mathrm{W}\right)$.
} 
a) Atlantic jet, winters 1996, 2005, 2010 (negative ZJI)

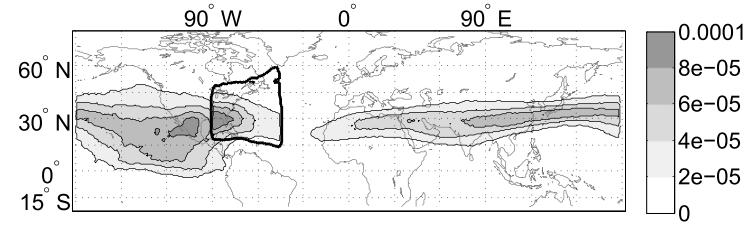

c) Atlantic jet, winters 1997, 2006-9 (positive ZJI)

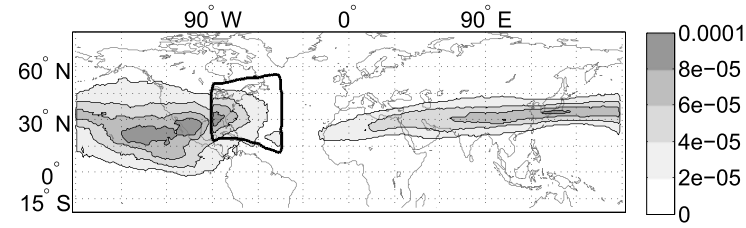

e) Atlantic jet, negative minus positive ZJI winters

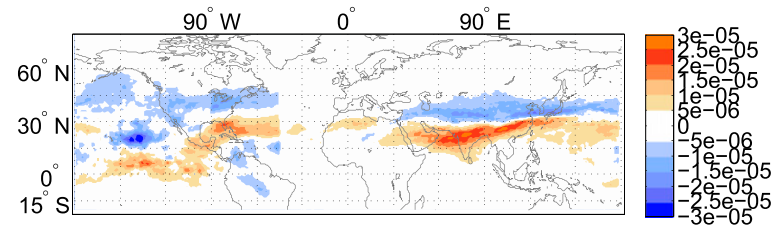

b) African jet, winters 1996, 2005, 2010 (negative ZJI)

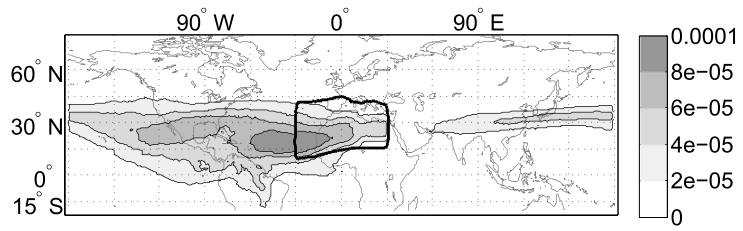

d) African jet, winters 1997, 2006-9 (positive ZJI)

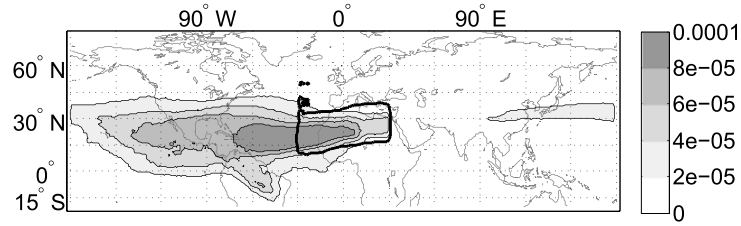

f) African jet, negative minus positive ZJI winters

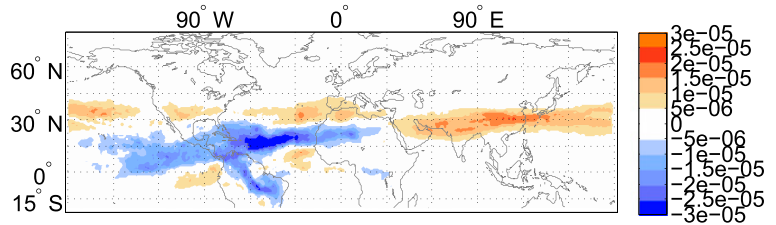

FIG. 9. A 168-h back-trajectory analysis starting from the (a),(c),(e) western Atlantic $\left(90^{\circ}-45^{\circ} \mathrm{W}\right)$ and (b),(d),(f) African $\left(30^{\circ} \mathrm{W}-30^{\circ} \mathrm{E}\right)$ subtropical jet regions. Shown is the fraction of the total number of trajectories that cross each grid point over the entire 7-day period, averaged over (a),(b) the negative ZJI winters of 1996, 2005, and 2010 and (c),(d) the five winters of 1997 and 2006-09. The bold contours correspond to a fraction $5 \times 10^{-5}$ on the day when the trajectories are started, and they roughly indicate the starting regions. The difference of the negative ZJI winters (1996, 2005, and 2010) minus 1997 and 2006-09 for the (e) Atlantic and (f) African jets.

from far-upstream sources (Asia and the Pacific), compared to closer-upstream air (the western subtropical Atlantic) during the negative ZJI winters, consistent with the merged jet structure.

\section{Connection to Atlantic SST}

The winter of 2010 was also characterized by strong North Atlantic SST anomalies (Fig. 7f) (Taws et al. 2011; Buchan et al. 2014). Figures 10a,b show the composites of SST anomalies and their meridional gradients in the North Atlantic region for the anomalously negative ZJI winter months, using monthly ERSST data (Smith et al. 2008) ranging from 1949 to 2012 . We also show the line of peak positive lower-level wind anomalies (thick black line in Figs. 10a,b) calculated from the negative ZJI composite of 925-700-hPa zonal wind anomalies. ${ }^{3} \mathrm{We}$ see a significant North Atlantic tripole anomaly, with warm SSTs in the tropics and just south of Greenland and cold water in between, with the line of maximum lower-level westerlies slightly equatorward of the peak

\footnotetext{
${ }^{3}$ The $10-\mathrm{m}$ wind anomalies give similar results.
}

cold SST anomalies. This SST anomaly pattern is quite typical of the ocean response during negative NAO conditions (e.g., Visbeck et al. 2003). The tropical warm anomaly extends from the eastern tropical Atlantic, where variability was found to be strongly correlated to ENSO (Enfield and Mayer 1997), all the way to the western coast of Africa. The meridional SST gradients are enhanced (more negative) in the subtropics (Fig. 10b). In the eastern Atlantic, the anomalous negative gradients coincide with the line of maximum anomalous lower-level westerlies, suggesting there is a possible positive SST-wind feedback in this region. The SST anomalies last more than a month, with the high-latitude and midlatitude anomalies starting to diminish at lag 2 months and the subtropical warm anomaly lasting even 3 months (not shown). While the SST anomaly pattern is quite typical of negative NAO conditions (e.g., Visbeck et al. 2003), a closer examination shows that during the more persistent negative ZJI winters, the SST gradients in the eastern subtropical Atlantic tend to be more anomalous than during typical negative NAO conditions. Figure 10c shows the winter-mean time series of the anomalous meridional SST gradients averaged over a box in the eastern subtropical Atlantic $\left(24^{\circ}-34^{\circ} \mathrm{N}, 20^{\circ}-50^{\circ} \mathrm{W}\right.$; the blue box marked on Fig. 10b) in the region where the SST 
a) Month 0 SST anomaly

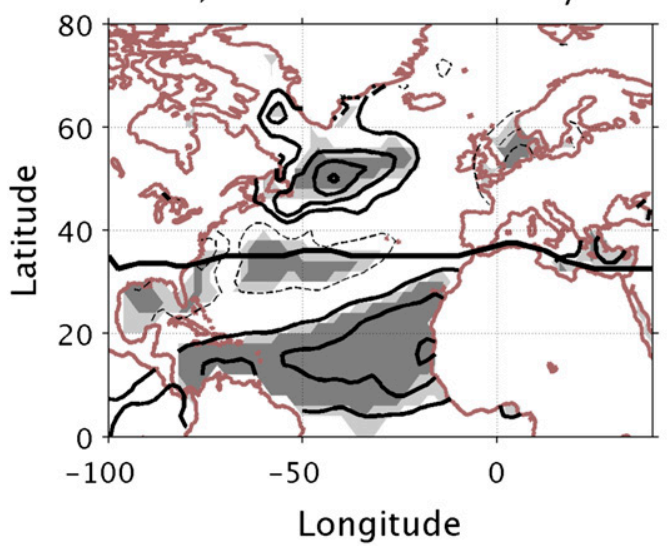

b) Month 0 SST gradient anomaly

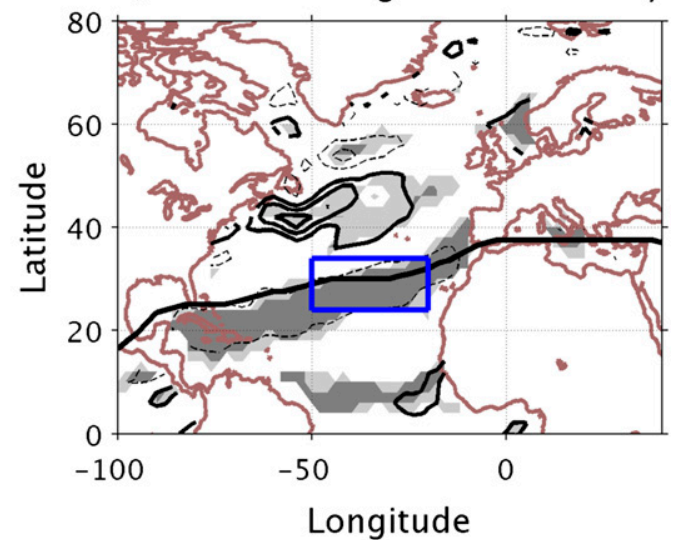

$\times 10^{-7} \quad$ c) Dec-Mar mean anomalous SST gradients (50W-20W, $\left.24 \mathrm{~N}-34 \mathrm{~N}\right)$

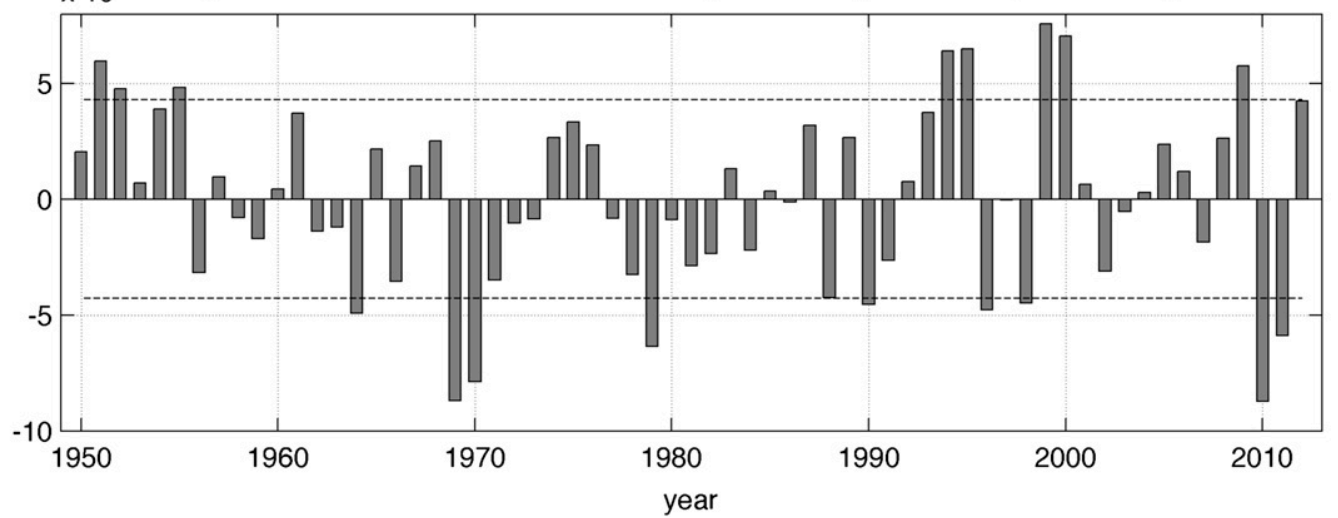

FIG. 10. The negative ZJI composites of (a) SST anomalies and (b) meridional gradients of the SST anomaly. Also shown in (a),(b) is the line of maximum positive lower-level (925-700-hPa mean) wind anomalies. (c) The DecemberMarch-mean meridional SST gradients, averaged over $24-34^{\circ} \mathrm{N}, 50-20^{\circ} \mathrm{W}$, marked by the blue box in (b). Dashed lines mark \pm one std dev. In the composite plots, the light and dark gray shadings mark the $95 \%$ and $99 \%$ significance regions, respectively. Negative values are dashed, and the zero contour is omitted. The contour interval is $0.15 \mathrm{~K}$ for SST and $3 \times$ $10^{-7} \mathrm{~K} \mathrm{~m}^{-1}$ for SST gradients.

gradients are aligned with the anomalous strong surface winds. We see two pairs of consecutive winters with very negative gradients-2010-11 and 1969-70-in which negative gradients are stronger during the first winter. Using subsurface ocean data, Taws et al. (2011) showed that the SST anomalies during 2010 were strong enough to affect the more persistent subsurface ocean and reemerge the following winter. They further suggested that this reemergence contributed to the anomalously negative NAO during early winter 2011. Though we do not have early subsurface observations, the time series suggest this reemergence mechanism could also have occurred during 1969 and 1970, with the anomalous SST contributing to the anomalous jet state during the winter of 1970. Examining the winter-mean ZJI time series (Fig. 4b), we see that indeed these winters were all characterized by a negative ZJI (though in 2011 it lasted only during November-December). Moreover, we see a clear coincidence between negative winter-mean ZJI and strongly negative winter-mean SST gradient index (e.g., winters of 1964, 1969, 1970, 1996, and 2010). This suggests that anomalously persistent zonal wind anomalies during zonal jet years act to induce large eastern subtropical Atlantic SST anomalies. These large SST anomalies, in turn, could also strengthen the wind anomalies (cf. Nakamura et al. 2004, 2008). While more studies need to be done to establish it, a positive SST-jet feedback could explain the strong persistence of the zonal-mean wind anomalies during some of the negative ZJI episodes. Recently, Buchan et al. (2014) examined the role of Atlantic SST anomalies in forcing the negative NAO during the winter of 2010 and early winter 2011 using a coupled GCM and found a significant role only for the early winter 2011. They, however, emphasized the role of SSTs in initiating the negative NAO conditions and did not examine their role in increasing NAO 


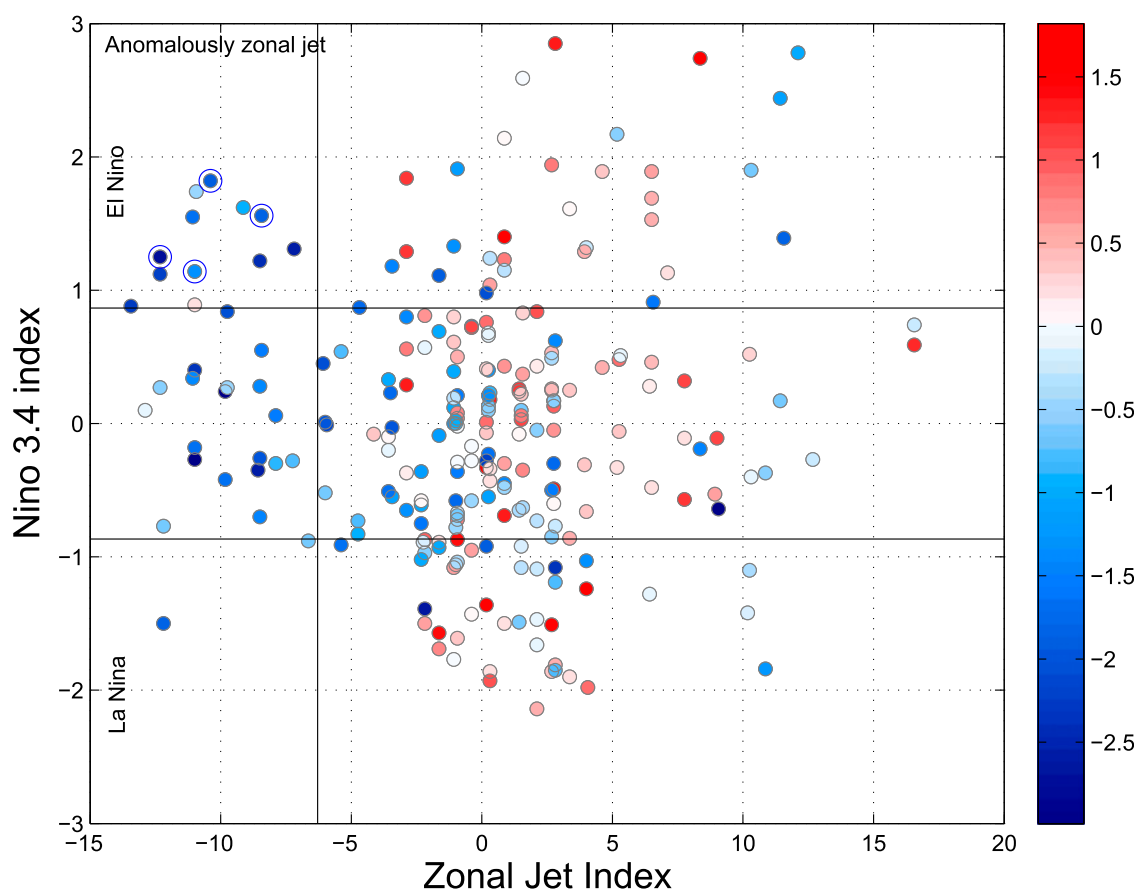

FIG. 11. Scatterplot of the monthly Niño-3.4 index vs the ZJI. Colors mark the normalized NAO index value with negative NAO in blue and positive NAO in red. Large circles show December 2009-March 2010. Anomalously zonal jet months have ZJI values smaller than -1 std dev, which is marked by the vertical black line. The \pm 1 std dev lines of the Niño- 3.4 index are marked by the horizontal black lines.

persistence; thus, their results are not inconsistent with our findings.

\section{Connection of ZJI to other atmospheric indices}

The results of previous sections suggest El Niño conditions contributed to the onset of the anomalously zonal jet state by strengthening the thermal forcing of the jet. We also saw a strong resemblance of negative ZJI months to a negative NAO state. In this section, we examine the statistical relation between the ZJI, the NAO index, and ENSO. Figure 11 shows a scatterplot of monthly Niño-3.4 index values against monthly ZJI values, with the colors marking the NAO index (negative NAO in blue and positive NAO in red). We see that, except for one month, jets with a strongly negative ZJI are in a negative NAO state, while positive ZJI months occur more with a positive NAO. This explains the similarity between the negative ZJI composites and NAO composites. On the other hand, not all negative NAO states are characterized by a zonal jet.

We also see that, with the exception of one month, anomalously zonal jets (ZJI smaller than -1 standard deviation) have not occurred during a strong La Niña, suggesting La Niña conditions are detrimental to the merging of the Atlantic and African jets. This is consistent with the notion that the merging of these jets is due to the eddy and thermal jet forcings both playing a role in forcing the jet during these years. The relation between ENSO and the ZJI, however, is complex. In particular, it seems to be different during positive and negative NAO months, with ENSO and ZJI being slightly positively correlated during positive NAO months (correlation of $0.17 ; 92 \%$ significance) and slightly (but not significantly) correlated during negative NAO months (correlation of -0.10 ). This is consistent with the idea that, under the right conditions of weak-enough eddies that have not shifted the jet too far poleward (a negative NAO), tropical heating can zonalize the Atlantic jet by inducing a merged thermally-eddy-driven jet state.

\section{Summary and conclusions}

We have shown that the northern winter of 2010 (December 2009-March 2010) was characterized by an anomalously zonal jet, in which the Atlantic jet shifted slightly southward and assumed a more zonal position, while the African subtropical jet shifted slightly poleward so that the two jets connected to form one elongated zonal jet. Moreover, the latitude-height structure and temporal variability of the Atlantic jet were more 
characteristic of the Pacific than the Atlantic during this winter. In the context of characterizing the jet stream types (e.g., Son and Lee 2005), it seems that during this winter, the jet changed from being eddy-driven to being a mixed eddy-thermally driven jet. This paper examines the possible transition of the Atlantic jet stream from an eddy-driven to a merged jet, as part of the large interannual variability in the Atlantic. We defined a zonal jet index (ZJI), which characterizes the zonal gradient in the latitude of the jet axis with anomalously negative values representing anomalously zonal jets. Calculating this index for monthly data allows us to identify zonal jet months. We find that, while an unusually zonal state occurs occasionally for a month, it is quite rare for it to be dominant for a whole winter, with the last occurrence before 2010 being the winters of 1969 and 1970. A composite analysis of various eddy quantities in comparison to the climatology shows a picture similar to a negative NAO state, with eddies and eddy fluxes being weaker and shifted anomalously south. A composite analysis of various quantities related to diabatic heating, including total atmospheric column heating, precipitation, vertical velocities, and anomalous SSTs, show anomalous heating in the tropical Pacific. This suggests the combination of weaker eddies and enhanced tropical heating, with positive eddy-mean flow feedbacks, push the jet from being eddy-driven to being partly thermally driven as in the Pacific (Li and Wettstein 2012). A Lagrangian backtrajectory analysis of the African and Atlantic jets shows that indeed the tropical Pacific is one of the sources of momentum for both jets, and during negative ZJI years, this source is enhanced relative to other years. We note that a significantly enhanced tropical Pacific heating is only found for the strongest negative ZJI winters; thus; apart from the winter of 2009/10, data prior to 1979 are needed in order to see it clearly.

A composite of SST anomalies shows a typical Atlantic tripole pattern (with a phase characteristic of a negative NAO pattern) but with particularly anomalous meridional gradients in the eastern subtropical Atlantic, where the surface wind is anomalously westerly. Previous studies found a strong SST feedback over the Gulf Stream region (e.g., Ciasto and Thompson 2004). We find that, when the anomalous meridional gradients become negative enough in the eastern subtropical Atlantic, an anomalously zonal jet state persists, suggesting a positive SST feedback, but in the eastern subtropical and midlatitude Atlantic. Moreover, the SST gradient anomalies in the observational record appeared in pairs of two consecutive winters: 1969-70 and 2010-11, with the earlier winters showing stronger anomalies, which suggests that these strong anomalies reach the deep waters and reemerge to strengthen the zonal jet state during the following winter (as in Taws et al. 2011).

Thus, the picture that emerges is that the Atlantic jet undergoes typical variations associated with eddy-mean flow interactions, which give rise to the typical Atlantic variability associated with the NAO. During a few winters, when an anomalously equatorward jet coincides with anomalous tropical heating, the jet can undergo a transition to a mixed thermally-eddy-driven jet state, which is more characteristic of the Pacific. Woollings et al. (2010b) examined the distribution of NAO phases and attributed the observed skewness to the existence of two different flow regimes-a "Greenland Blocking" pattern more characteristic of a negative NAO and a "sub-polar jet" state more characteristic of a positive NAO_each of which exhibits variability with a Gaussian distribution. The relation between Greenland Blocking and the type of jet stream is left for a future study.

Acknowledgments. We acknowledge support received from Israeli Science Foundation Grants 1370/08 and 1537/ 12. O. Adam acknowledges an Israeli VATAT postdoctoral grant. GPCP precipitation data was provided by the NOAA/OAR/ESRL PSD from their website at http:// www.esrl.noaa.gov/psd/. We thank Eyal Heifetz for insightful discussions. Most of the calculations presented here were performed using the Geophysical Observation Analysis Tool (GOAT), a freely available MATLABbased tool for management, analysis, and visualization of geophysical data (http://www.goat-geo.org).

\section{REFERENCES}

Adler, R. F., and Coauthors, 2003: The Version-2 Global Precipitation Climatology Project (GPCP) monthly precipitation analysis (1979-present). J. Hydrometeor., 4, 1147-1167, doi:10.1175/1525-7541(2003)004<1147:TVGPCP > 2.0.CO;2.

Barnston, A. G., and R. E. Livezey, 1987: Classification, seasonality and persistence of low-frequency atmospheric circulation patterns. Mon. Wea. Rev., 115, 1083-1126, doi:10.1175/ 1520-0493(1987)115<1083:CSAPOL > 2.0.CO;2.

Bordoni, S., and T. Schneider, 2010: Regime transitions of steady and time-dependent Hadley circulations: Comparison of axisymmetric and eddy-permitting simulations. J. Atmos. Sci., 67, 1643-1654, doi:10.1175/2009JAS3294.1.

Buchan, J., J. J.-M. Hirschi, A. T. Blaker, and B. Sinha, 2014: North Atlantic SST anomalies and the cold north European weather events of winter 2009/10 and December 2010. Mon. Wea. Rev., 142, 922-932, doi:10.1175/MWR-D-13-00104.1.

Cattiaux, J., R. Vautard, C. Cassou, P. Yiou, V. Masson-Delmotte, and F. Codron, 2010: Winter 2010 in Europe: A cold extreme in a warming climate. Geophys. Res. Lett., 37, L20704, doi:10.1029/2010GL044613.

Ciasto, L. M., and D. W. J. Thompson, 2004: North Atlantic atmosphere-ocean interaction on intraseasonal time scales. J. Climate, 17, 1617-1621, doi:10.1175/1520-0442(2004)017<1617: NAAIOI $>2.0 . \mathrm{CO} ; 2$. 
Dee, D. P., and Coauthors, 2011: The ERA-Interim reanalysis: Configuration and performance of the data assimilation system. Quart. J. Roy. Meteor. Soc., 137, 553-597, doi:10.1002/ qj.828.

Eichelberger, S. J., and D. L. Hartmann, 2007: Zonal jet structure and the leading mode of variability. J. Climate, 20,5149-5163, doi:10.1175/JCLI4279.1.

Enfield, D. B., and D. A. Mayer, 1997: Tropical Atlantic sea surface temperature variability and its relation to El Niño-Southern Oscillation. J. Geophys. Res., 102, 929-945, doi:10.1029/ 96JC03296.

Held, I. M., 1975: Momentum transport by quasi-geostrophic eddies. J. Atmos. Sci., 32, 1494-1497, doi:10.1175/ 1520-0469(1975)032<1494:MTBQGE > 2.0.CO;2.

- 2000: The general circulation of the atmosphere. Program in Geophysical Fluid Dynamics, J.-L. Thiffeault, Ed., Vol. 2000, Woods Hole Oceanographic Institution, 1-54. [Available online at http://www.gfdl.noaa.gov/cms-filesystem-action/user_files/ih/ lectures/woods_hole.pdf.]

_ , and A. Y. Hou, 1980: Nonlinear axially symmetric circulations in a nearly inviscid atmosphere. J. Atmos. Sci., 37, 515-533, doi:10.1175/1520-0469(1980)037<0515:NASCIA >2.0.CO;2.

Kalnay, E., and Coauthors, 1996: The NCEP/NCAR 40-Year Reanalysis Project. Bull. Amer. Meteor. Soc., 77, 437-471, doi:10.1175/1520-0477(1996)077<0437:TNYRP>2.0.CO;2.

Koch, P., H. Wernli, and H. C. Davies, 2006: An event-based jetstream climatology and typology. Int. J. Climatol., 26, 283-301, doi:10.1002/joc. 1255 .

Lachmy, O., and N. Harnik, 2014: The transition to a subtropical jet regime and its maintenance. J. Atmos. Sci., 71, 1389-1409, doi:10.1175/JAS-D-13-0125.1.

Lee, S., and H.-K. Kim, 2003: The dynamical relationship between subtropical and eddy-driven jets. J. Atmos. Sci., 60, 1490-1503, doi:10.1175/1520-0469(2003)060<1490:TDRBSA > 2.0.CO;2.

Li, C., and J. J. Wettstein, 2012: Thermally driven and eddy-driven jet variability in reanalysis. J. Climate, 25, 1587-1596, doi:10.1175/JCLI-D-11-00145.1.

Martius, O., 2014: A Lagrangian analysis of the Northern Hemisphere subtropical jet. J. Atmos. Sci., 71, 2354-2369, doi:10.1175/JAS-D-13-0329.1.

— physical and dynamical processes that govern the temporal evolution of the subtropical jet streams over Africa. J. Atmos. Sci., 69, 1602-1616, doi:10.1175/JAS-D-11-0190.1.

Nakamura, H., and T. Sampe, 2002: Trapping of synoptic-scale disturbances into the North-Pacific subtropical jet core in midwinter. Geophys. Res. Lett., 29, 1761, doi:10.1029/ 2002 GL015535.

,,-- Y. Tanimoto, and A. Shimpo, 2004: Observed associations among storm tracks, jet streams and midlatitude oceanic fronts. Earth's Climate, Geophys. Monogr., Vol. 147, Amer. Geophys. Union, 329-345.

- - - A. Goto, W. Ohfuchi, and S.-P. Xie, 2008: On the importance of midlatitude oceanic frontal zones for the mean state and dominant variability in the tropospheric circulation. Geophys. Res. Lett., 35, L15709, doi:10.1029/ 2008GL034010.

O'Rourke, A., and G. K. Vallis, 2013: Jet interaction and the influence of a minimum phase speed bound on the propagation of eddies. J. Atmos. Sci., 70, 2614-2628, doi:10.1175/ JAS-D-12-0303.1.
Panetta, R. L., 1993: Zonal jets in wide baroclinically unstable regions: Persistence and scale selection. J. Atmos. Sci., 50, 2073-2106, doi:10.1175/1520-0469(1993)050<2073:ZJIWBU>2.0.CO;2.

Rhines, P. B., 1975: Waves and turbulence on a beta-plane. J. Fluid Mech., 69, 417-443, doi:10.1017/S0022112075001504.

Romanski, J., and W. B. Rossow, 2013: Contributions of individual atmospheric diabatic heating processes to the generation of available potential energy. J. Climate, 26, 4244-4263, doi:10.1175/ JCLI-D-12-00457.1.

Santos, J., T. Woollings, and J. Pinto, 2013: Are the winters 2010 and 2013 archetypes exhibiting extreme opposite behavior of the North Atlantic jet stream? Mon. Wea. Rev., 141, 36263640, doi:10.1175/MWR-D-13-00024.1.

Schneider, E. K., 1977: Axially symmetric steady-state models of the basic state for instability and climate studies. Part II. Nonlinear circulations. J. Atmos. Sci., 34, 280-296, doi:10.1175/ 1520-0469(1977)034<0280:ASSSMO > 2.0.CO;2.

Seager, R., Y. Kushnir, J. Nakamura, M. Ting, and N. Naik, 2010: Northern Hemisphere winter snow anomalies: ENSO, NAO and the winter of 2009/10. Geophys. Res. Lett., 37, L14703, doi:10.1029/2010GL043830.

Smith, T., and R. Reynolds, 2004: Improved extended reconstruction of SST (1854-1997). J. Climate, 17, 2466-2477, doi:10.1175/1520-0442(2004)017<2466:IEROS > 2.0.CO;2.

,$- \ldots$, T. C. Peterson, and J. Lawrimore, 2008: Improvements to NOAA's historical merged land-ocean surface temperature analysis (1880-2006). J. Climate, 21, 2283-2296, doi:10.1175/ 2007JCLI2100.1.

Son, S. W., and S. Lee, 2005: The response of westerly jets to thermal driving in a primitive equation model. J. Atmos. Sci. 62, 3741-3757, doi:10.1175/JAS3571.1.

Taws, S. L., R. Marsh, N. C. Wells, and J. Hirschi, 2011: Reemerging ocean temperature anomalies in late-2010 associated with a repeat negative NAO. Geophys. Res. Lett., 38, L20601, doi:10.1029/2011GL048978.

Trenberth, K. E., and A. Solomon, 1994: The global heat balance: Heat transports in the atmosphere and ocean. Climate Dyn., 10, 107-134, doi:10.1007/BF00210625.

Uppala, S. M., and Coauthors, 2005: The ERA-40 Re-Analysis. Quart J. Roy. Meteor. Soc., 131, 2961-3012, doi:10.1256/qj.04.176.

Vicente-Serrano, S. M., R. M. Trigo, J. I. López-Moreno, M. L. R. Liberato, J. Lorenzo-Lacruz, S. Begueria, E. Morán-Tejeda, and A. E. Kenawy, 2011: Extreme winter precipitation in the Iberian Peninsula in 2010: Anomalies, driving mechanisms and future projections. Climate Res., 46, 51-65, doi:10.3354/ cr00977.

Visbeck, M., E. P. Chassignet, R. G. Curry, T. L. Delworth, R. R. Dickson, and G. Krahmann, 2003: The ocean's response to North Atlantic Oscillation variability. The North Atlantic Oscillation: Climatic Significance and Environmental Impact, Geophys. Monogr., Vol. 134, Amer. Geophys. Union, 113-145.

Wang, C., H. Liu, and S.-K. Lee, 2010: The record-breaking cold temperatures during the winter of 2009/2010 in the Northern Hemisphere. Atmos. Sci. Lett., 11, 161-168, doi:10.1002/ asl.278.

Woollings, T., A. Hannachi, and B. Hoskins, 2010a: Variability of the North Atlantic eddy-driven jet stream. Quart. J. Roy. Meteor. Soc., 136, 856-868, doi:10.1002/qj.625.

,,--- , and A. Turner, 2010b: A regime view of the North Atlantic Oscillation and its response to anthropogenic forcing. J. Climate, 23, 1291-1307, doi:10.1175/2009JCLI3087.1. 